volume will be pleased with their ability to retain useful information from this well-structured, current review of topics important to neurosurgical residents, fellows, and consultants alike. Those appearing for their certification examinations, and those looking for a quick, ready reference on fundamental knowledge in neurosurgery would be wise to keep this volume on their bookshelf.

\author{
Shobhan Vachhrajani \\ Toronto, Ontario, Canada
}

The Neuroscience of Religious ExPerience. 2009. By Patrick McNamara. Published by Cambridge University Press. 301 pages. $\mathrm{C} \$ 90$ approx.
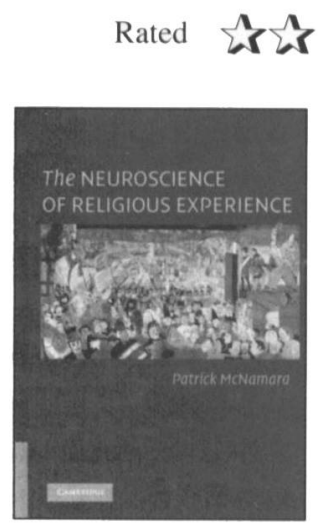

Prior to becoming a neurologist, my first career was in theology, spirituality, and comparative religion. Given my background, I am easily lured by the dialogue between religion and neuroscience, and I have a decent collection of books on the combined subjects. Surprisingly, I have rarely ever been able to finish reading a book that explores what should be a profound connection. Somehow I just can't get as excited by the combination of topics as I can by either topic alone.

I forced myself to finish reading Patrick McNamara's book, but unfortunately I again have been left feeling very dissatisfied by what should be a captivating conversation between science and religion. As Albert Einstein said, "Science without religion is lame, and religion without science is blind." Nevertheless, the dialogue between the two has once again left me feeling both lame and blind. Of course that may say more about me than about Patrick McNamara's book, but I will attempt to dispassionately explain what I liked, and what I did not like, about "The Neuroscience of Religious Experience".

I liked how the author develops an original theory of the self, the divided self, and the self's relationship to God. He describes a process which he calls "decentering" to which he applies a neurological model of familiar aspects of brain function, neurochemistry, and functional neuroimaging. The essence of his theory is that religion is a powerful tool which can allow an individual to "decenter" in such a way that allows selftransformation. McNamara presents some evidence that the "neurology" of religious experience occurs via the neural networks between the amygdala, the prefrontal cortex, and the anterior temporal lobes particularly on the right side of the brain. I liked this central thesis, and appreciated some of the ways in which he develops his theory.

Unfortunately this book is too much of a good thing. It is excessively wordy, painfully poorly written, and reads much more like a PhD thesis in psychology than as a credible contribution to the literature of either neuroscience or religion. It probably deserves a place within the psychology literature, since this work is really a psychologist's treatise. For the neurologist there is very little recognizable "neuroscience", and for the religious person there is very little that inspires. The content of the book oscillates between pedantic psychological opinion on the "Self" and fragments of contemporary neuroscience, but there is little cohesive and substantial content to bind the author's message together. I think McNamara's points could have been made much more simply, clearly, and briefly, and that the key concepts in the book lose a lot of their potential power because they are lost in the translation. This may also be a reflection of some underlying muddled thinking and off-hand conceptualizing about topics that are by their nature mysterious and not necessarily within reach of the rational mind. It is almost impossible to engage in a dialogue between religion and science without reducing the mystery of existence and the human spirit to a mere biology of religion.

This book will join the other enticing and attractive books on religion and the brain on the shelf, but I think the money would be better spent helping widows and orphans.

Edward J. Atkins Saskatoon, Saskatchewan, Canada

Carotid Artery Stenting: The Basics. 2009. Edited by Jacqueline Saw. Published by Humana Press (a part of Springer Science and Business Media). 276 pages. C\$200 approx.

\section{Rated trots}

The editor intends this book to be "a learning resource on the multifaceted management of patients with carotid artery stenosis, with key focus on extracranial carotid artery stenting." It is meant to "complement the "hands-on" experience of interventional trainees and established interventionists."

The book has six parts, each part authored or co-authored by neurologists, vascular surgeons, one radiologist, and interventional cardiologists.

The first part comprises known information about stroke and TIA, as well as a history of various trials and medications used to prevent or treat stroke. The reader is given an overview of carotid endarterectomy, technique and indications.

The second part comprises imaging, both pre-procedural and intraprocedural, of the arterial circulation, with sections on the catheterization laboratory, and on non-invasive imaging of the extracranial carotid circulation.

The third part describes patient selection, pre-procedural patient preparation, and operator training and accreditation.

The fourth part describes routes of vascular access for stenting, 